\title{
Concentrations of Follicle-Stimulating Hormone Correlate with Alkaline Phosphatase and a Marker for Vitamin K Status in the Perimenopause
}

\author{
JANE L. LUKACS, Ph.D., R.N.,1 and NANCY E. REAME, Ph.D., R.N., F.A.A.N.1,2
}

\section{ABSTRACT}

Serum alkaline phosphatase (ALP), a gross marker of bone turnover, has been reported to be elevated after menopause, a period characterized by hallmark increases in follicle-stimulating hormone (FSH). Whether the ALP rise coincides with the perimenopausal transition when changes in FSH, estrogen levels, and menstrual cycles are first apparent is not known. The purpose of this cross-sectional study was twofold: (1) to characterize the influence of the perimenopausal transition on ALP activity and (2) to correlate ALP activity with more precise markers for bone, osteocalcin (OC), and vitamin $\mathrm{K}$ status assessed with undercarboxylated osteocalcin (ucOC). Thirty-eight studies of hourly FSH were conducted on cycle day 6 of the follicular phase in perimenopausal women volunteers, aged 40-54 years (mean body mass in$\operatorname{dex}[B M I]=24.2 \pm 0.5)$. Mean FSH was used to define the perimenopausal stage (early perimenopausal, mean FSH $\leq 15 \mathrm{IU} / \mathrm{L}, n=27$; late perimenopausal, mean FSH $>15 \mathrm{IU} / \mathrm{L}, n=11$ ). As expected, late perimenopausal women had irregular and longer menstrual cycles, lower estradiol $\left(E_{2}\right)$ and estrone $\left(E_{1}\right)$ levels, and a lower frequency of ovulations vs. the early group. ALP was higher $(76.5 \pm 8.3$ vs. $58.3 \pm 2.7 \mathrm{IU} / \mathrm{L}, p=0.045)$ compared with the early perimenopausal group. In a subsample $(n=10)$, OC was associated with ALP $(r=0.69, p<0.03)$, FSH was positively related to ucOC concentrations $(r=0.7, p<0.03)$, and women with $\mathrm{E}_{1}$ concentrations $<40 \mathrm{pg} / \mathrm{ml}$ had double the percentage of ucOC compared with those where $E_{1}$ was $>40 \mathrm{pg} / \mathrm{ml}(46.3 \% \pm 6.6 \%$ vs. $22.0 \% \pm 3.1 \%, p<0.006)$. Clinical markers of the perimenopause are associated with a nonspecific but inexpensive marker of enhanced bone turnover (i.e., higher ALP) and correlate well with more precise markers of bone activity. These findings suggest that health-promotion strategies for preserving bone should be instituted well before the last menstrual period.

\section{INTRODUCTION}

$\mathbf{T}$ HE RAPID BONE LOSS after menopause brought on by the dramatic decline in estradiol $\left(\mathrm{E}_{2}\right)$ has become one of the major reasons for treatment of postmenopausal women with hormone replacement therapy (HRT). ${ }^{1,2}$ Little is known, however, about the nature and time course of the menopause-mediated bone loss or whether preemptive signs may exist in women approaching their last menstrual cycles.

The years before menopause (perimenopause transition) have only recently been studied but are now considered to be a time of dramatic fluc-

${ }^{1}$ School of Nursing and ${ }^{2}$ Reproductive Science Program, University of Michigan, Ann Arbor, Michigan.

Supported by NUR01 01373, 5-R01-AG15083-03,5-M01-RR-00042, and NR07309-01A1 and the University of Michigan Rackham Dissertation Fund. 
tuations in both gonadotropins and ovarian steroids because of the diminished influence of the ovarian follicular reserve and, thus, loss of tight negative feedback, which is responsible for the regular cyclicity of the menstrual cycle. ${ }^{3,4}$ In response to rising follicle-stimulating hormone (FSH) levels, the ovary intensifies its production of estrogen despite a decline in the number of follicles, and episodes of hyperestrogenism have been reported in the perimenopause. ${ }^{4}$

A number of bone biomarkers in both blood and urine have been used to assess bone turnover in the menopause, with varying levels of precision. ${ }^{5-7}$ Although state-of-the-art assays have been developed that identify the isoenzyme bonespecific (ALP), these tests are expensive and seldom are included in a routine medical examination. Healthy women are more likely to have a measure of serum ALP (a less specific marker of osteoblast activity). A rise in serum ALP has been associated with decreased bone mineral density in postmenopausal women (mean age $59.1 \pm 0.3$ years) .8

Only a few studies to date have examined the relationship between markers of early reproductive aging (i.e., prior to menopause) and bone function. Slemenda et al. ${ }^{9}$ reported significant bone loss in irregularly cycling perimenopausal women in a longitudinal, 3-year study. However, the significance of these findings is not clear because data from the perimenopausal subjects were combined with data from postmenopausal women to predict rate of bone loss in order to limit the impact of occasional high estrogen measurements and low bone loss rates.

In a cross-sectional study of bone-related variables in women at different stages of the perimenopausal transition, a marked elevation of ALP was present only in subjects with FSH values $>40 \mathrm{IU} / \mathrm{L}^{10}{ }^{10}$ Perimenopausal women with FSH values between 20 and $40 \mathrm{IU} / \mathrm{L}$ showed essentially similar concentrations to premenopausal subjects. In this study, single measures of FSH were obtained at random on the day of the clinic visit and not drawn at an equivalent phase in the menstrual cycle, thus raising questions about the reliability of the gonadotropin characterization. Moreover, retrospective recall in this and other studies has been the only method used to assess cycle length. Thus, the current understanding of how the dynamic hormone changes during the perimenopause relate to bone turnover remains obscure.
To clarify the relationship between reproductive aging prior to menopause and bone loss, we undertook a cross-sectional study of selected bone biomarkers in perimenopausal women using an intensive blood-sampling protocol to more precisely define reproductive hormones during the early follicular phase and prospective charting to monitor menstrual cycle length. We hypothesized that the measurement of serum ALP, an inexpensive and commonly obtained laboratory test in clinical practice, may have some utility for monitoring perimenopausal bone activity.

Osteocalcin (OC), a bone protein secreted by osteoblasts, is a new specific biomarker of bone turnover. ${ }^{11}$ The level of OC that would indicate bone turnover in the postmenopause is not well defined, as osteoporotic women have values that extend throughout and just beyond the normal range. ${ }^{12}$ Moreover, lack of a standardized commercial assay complicates comparison of concentrations among studies. ${ }^{13}$

Undercarboxylated osteocalcin (ucOC) is a precise indicator of vitamin $\mathrm{K}$ status. It reflects vitamin $\mathrm{K}^{\prime} \mathrm{s}$ role in carboxylating glutamic acid residues on the protein that subsequently facilitates the binding of OC to hydroxyapatite in bone. ${ }^{14-16}$ Both OC and ucOC can be measured in the same assay.

Until now, OC assays were designed to monitor supraphysiological concentrations in disease states. In addition, older assays were limited by their inability to distinguish the intact molecule from fragments. ${ }^{17}$ Recently, a new assay specific for the intact protein has been developed. As a secondary aim of this study, we set out to establish the feasibility of using a modified assay specific for the intact OC protein to measure physiological concentrations present in healthy women. The undercarboxylated form was also examined for changes during the climacteric years.

\section{MATERIALS AND METHODS}

Before initiation of the study, approval of the clinical protocol was obtained from the University of Michigan Hospitals Institutional Review Board (IRB) for use with human subjects. All volunteers provided written informed consent. This study was undertaken as part of a larger study of the effects of HRT on the neuroreproductive axis of perimenopausal women (NIH grant NUR01 01373, N. Reame, P.I.). 


\section{Subjects}

At the time of recruitment, 37 subjects met the following eligibility criteria: aged 40 or older, intact uterus and ovaries, a screening body mass index (BMI) of $20-30 \mathrm{~kg} / \mathrm{m}^{2}$, a spontaneous menstrual cycle within the preceding 6 months, a history of normal menstrual cycles and at least one pregnancy carried to term, normal endocrine screen, no current medical or psychiatric illness, no current use of oral contraceptives, no pregnancy or breastfeeding in the past 6 months, and no current history of dieting, excessive exercise, or alcohol consumption. One normal cycling subject was studied again 38 months later when she was experiencing irregular cycles, yielding a total of 38 studies. For the substudy of OC and ucOC, values from 1 subject (postmenopausal) whose last menstrual cycle was 18 months prior to the study was included for comparison with 9 perimenopausal subjects.

\section{Study protocol}

Subjects were admitted between cycle days 4 and 8 to the outpatient division of the General Clinical Research Center of the University of Michigan Hospitals for an 8-hour intensive blood-sampling protocol (0900-1700 hours). To assess general health status, subjects underwent a psychosocial and medical health interview. They also kept a daily diary of menstrual symptoms/bleeding and medication usage for up to 45 days. In all subjects, the results of screening studies for hemoglobin, hematocrit, liver function, insulin, glucose, and serum cholesterol were in the normal range for healthy volunteers after an overnight fast.

During the 8-hour study, blood samples were obtained through an indwelling intravenous (i.v.) forearm catheter every 10 minutes to assess pulsatile luteinizing hormone ( $\mathrm{LH}$ ) secretion, hourly for FSH measures, and every 4 hours for $E_{2}$ and progesterone $(\mathrm{P})$ determinations. A fasting sample of blood was drawn at 0900 hours (just prior to the 8-hour sampling regimen) for determination of serum ALP, OC, ucOC, prolactin (PRL), total testosterone $(T)$, free $T$, estrone $\left(E_{1}\right)$, dehydroepiandrosterone sulfate (DHEAS), serum calcium, phosphate, albumin, thyroid-stimulating hormone (TSH), thyroxine $\left(\mathrm{T}_{4}\right)$, total triiodothyronine $\left(T_{3}\right)$ and liver enzymes, alanine aminotransferase (ALT), and aspartate aminotransferase (AST). Three single blood draws were collected at 1-week intervals following the follicular phase study day for measurement of $E_{2}$ and $P$ to determine the ovulatory status of the study cycle.

\section{Assays}

Reproductive Hormone Assays. Plasma $\mathrm{E}_{2}$ (assay sensitivity $5 \mathrm{pg} / \mathrm{ml}$ ) and $\mathrm{P}$ (assay sensitivity 0.2 $\mathrm{ng} / \mathrm{ml}$ ) were measured using radioimmunoassay (RIA) kits (Diagnostic Products Corp., Los Angeles, CA, and Radioassay Systems Laboratories, Carson, CA). All samples for a subject were measured in the same assay. Intraassay and interassay coefficient of variation (CV) for $\mathrm{E}_{2}$ was $5.1 \%$ and $9 \%$, respectively. Intraassay and interassay CV for $\mathrm{P}$ was $2.3 \%$ and $9.2 \%$, respectively. Plasma LH and FSH were determined by Delfia ${ }^{\circledR}$ fluorometric immunoassay (IFMA) (Wallac Inc., Gaithersburg, MD). All samples were measured in the same assay. Gonadotropin concentrations are reported as international units per liter (IU/L). The LH assay standard is calibrated against the World Health Organization (WHO) Second International Standard for pituitary LH for immunoassay 80/552. FSH is calibrated against the WHO Second International Reference Preparation of human pituitary $\mathrm{FSH} / \mathrm{LH}$ for bioassay 78/549. For LH and FSH assays, the limit of detection was $0.05 \mathrm{IU} / \mathrm{L}$, and the interassay $\mathrm{CV}$ was $6.8 \%$ and $4.8 \%$, respectively. For analysis, values below assay sensitivity were assigned the value of assay sensitivity.

ALP Assay. Fasting serum ALP was analyzed by the clinical ligand laboratory of the University of Michigan Hospitals, using the dry slide method, and read by a Vitros 900 Auto Analyzer (model 950)(Johnson \& Johnson, Rochester, NY). The assay sensitivity is $20 \mathrm{IU} / \mathrm{L}$, and the $\mathrm{CV}$ is $4.5 \%$.

OC and ucOC Assay. OC was measured using a modification of a previously validated immunoradiometric assay $\left(\mathrm{N}\right.$-tact ${ }^{\circledR}$ Osteo $\mathrm{SP}$ ) (Incstar, Stillwater, MN) that measures the intact protein. ${ }^{13}$ Plasma OC and ucOC were measured in a subset of subjects $(n=10$, the last 10 subjects studied). OC was measured in untreated plasma. For measurement of ucOC, $400 \mu$ l plasma sample was mixed with $8 \mathrm{mg}$ calcium phosphate tribasic (Mallinkrodt, Paris, KY) in micro-Eppendorf tubes, mixing end-over-end for 30 minutes at $4^{\circ} \mathrm{C}$ and centrifuging at $700 \mathrm{~g}$ for 20 minutes at $4^{\circ} \mathrm{C}$ 
(protocol modified from J. Suttie, University of Wisconsin-Madison). The ucOC was measured in the supernatant. This treatment allows separation of carboxylated and undercarboxylated species.

The assay modification involved extension of the standard curve from $1.5 \mathrm{ng} / \mathrm{ml}$ down to 0.20 $\mathrm{ng} / \mathrm{ml}$. All samples were run in two assays, with $\mathrm{OC}$ and ucOC for a given individual run in the same assay in duplicate. Kits shipped from the company within 5 days of iodination were used for the two assays. Sample volume size used in the assay was $100 \mu$ l per tube. Quality control (QC) checks included a perimenopausal plasma sample and a low control (human osteocalcin) provided with the kit, both treated with calcium phosphate tribasic (as described). The intraassay $\mathrm{CV}$ for the perimenopausal QC (average 0.72 $\mathrm{ng} / \mathrm{ml}, n=2$ ) was $2.7 \%$. The interassay $\mathrm{CV}$ for the low control QC (average $0.775 \mathrm{ng} / \mathrm{ml}, n=2$ ) was $1.3 \%$.

Assay sensitivity (2 standard deviations [SD] of buffer control) for the two assays analyzed was $0.09 \mathrm{ng} / \mathrm{ml}$. Plasma samples from a perimenopausal and a postmenopausal volunteer were diluted parallel to the standard curve in this modified version (slopes: standard $1.09 \pm$ 0.018 ; perimenopausal $1.11 \pm 0.03$; postmenopausal $1.11 \pm 0.017)$. Recovery of serial dilutions of kit standard and perimenopausal and postmeno-pausal samples averaged $74 \%-119 \%$. Intraassay and interassay $\mathrm{CV}$ averaged $6.8 \%$ and $9.1 \%$, respectively.

\section{Data analysis}

Definition of Study Groups. To examine the effects of reproductive aging, subjects were initially grouped as premenopausal (regular menstrual cycles, no menopausal complaints, $\mathrm{FSH} \leq 15$ $\mathrm{IU} / \mathrm{L}, n=14$ ), or perimenopausal (symptomatic women with irregular cycles). This latter group was further divided into an early $(n=13)$ and late $(n=11)$ perimenopausal group according to an FSH value of $15 \mathrm{IU} / \mathrm{L}$. This value has been used to define study groups in other studies of perimenopausal bone loss and is associated with low pregnancy rates in infertile patients. ${ }^{18} \mathrm{Be}-$ cause the normally cycling and early perimenopausal groups did not differ in BMI (23.4 \pm 0.5 vs. $24.5 \pm 0.7 \mathrm{~kg} / \mathrm{m}^{2}$, respectively, $p=\mathrm{NS}$ ) or FSH (10.1 \pm 0.8 vs. $8.5 \pm 1.2 \mathrm{IU} / \mathrm{L}$, respectively, $p=\mathrm{NS}), \mathrm{E}_{2}(47.9 \pm 7.3$ vs. $95.8 \pm 20.5 \mathrm{pg} / \mathrm{ml}$, respectively, $p=\mathrm{NS})$, and ALP $(59.7 \pm 2.9$ vs.
$56.8 \pm 4.8 \mathrm{IU} / \mathrm{L}$, respectively, $p=\mathrm{NS}$ ) concentrations, they were combined for all further analyses $(n=27)$ and are referred to as the early perimenopausal group.

Statistical Analysis. Physiological data are presented as mean $\pm \mathrm{SE}$. Mean values of FSH, LH, $E_{2}$, and $P$ were determined from the serial values obtained across the 8-hour daytime sampling interval during the follicular phase study. To adjust for differential binding of calcium by varying albumin levels, each subject's serum total calcium/albumin ratio was proportionally corrected to a standard albumin level of $4.2 \mathrm{~g} / \mathrm{dl}$, using the method of Garton et al. ${ }^{19}$ The percent of undercarboxylated osteocalcin (\% ucOC) is the calculated value:

$$
\% \text { ucOC }=\frac{\text { ucOC }}{\text { Total OC }} \times 100
$$

The distribution of physiological values was explored for normality. Where appropriate data transformation was used for skewed distributions (e.g., logarithmic transformation for sex steroid data, reciprocal transformation for ALP), transformation did not change the outcome of the results, and the transformation data are not reported. Correlation analysis was performed using Pearson $r$ test, and comparison between groups was made using Fisher's exact test (for frequencies), independent sample $t$ test, or Mann Whitney $U$ test. In two separate subanalyses on $\%$ ucOC and estrogen status, subject data were grouped by a cutoff of $20 \mathrm{pg} / \mathrm{ml}$ for $E_{2}$ and 40 $\mathrm{pg} / \mathrm{ml}$ for $\mathrm{E}_{1}$, based on reports of bone loss at these concentrations. ${ }^{9} p$ values were derived using the two-tailed tests conducted at the 0.05 level.

\section{RESULTS}

\section{Clinical characteristics}

At the time of the study, 31 of the 37 subjects (84\%) had experienced their most recent menstrual period within the past 3 months. In 5 others $(13 \%)$, the last menstrual period was within the past 5 months, and in 1 subject ( $3 \%$ ) the last menses was 9 months earlier. Of the 38 menstrual cycles assessed, 25 (66\%) were ovulatory, as determined by a midluteal $\mathrm{P}$ level $\geq 4 \mathrm{ng} / \mathrm{ml}$. 
Table 1 lists the clinical characteristics of the two groups of women, early perimenopausal $(\mathrm{FSH} \leq 15 \quad \mathrm{IU} / \mathrm{L})$ and late perimenopausal $(\mathrm{FSH}>15 \mathrm{IU} / \mathrm{L})$ during the follicular phase study. There were no significant differences between groups for age or body size characteristics. As expected, the late perimenopausal group had higher mean gonadotropin concentrations $(p<$ $0.001)$, lower plasma $E_{2}$ levels $(p=0.006)$, and lower $\mathrm{E}_{1}$ levels $(p<0.05)$.

FSH concentration had a significant effect on mean cycle length $(p<0.01)$; the positive correlation was significant $(r=0.66, p<0.001)$. Early perimenopausal women (FSH range 4-15 IU/L) had cycle lengths ranging from 15 to 63 days. In contrast, menstrual bleeding intervals ranged from 27 to 161 days in the late perimenopausal group (FSH range 20-98 IU/L). Anovulatory cycles were present in $73 \%$ of the late perimenopausal women, a higher rate than observed in the early perimenopausal group $(28 \%, p<$ 0.003).

No group differences were observed for PRL or DHEAS concentrations or in thyroid function or liver enzyme activity (ALT, AST). The expected effects of the perimenopause on $\mathrm{T}$ concentrations were observed. Serum phosphate did not differ between groups, but serum calcium, when corrected for a serum albumin of $4.2 \mathrm{~g} / \mathrm{dl}$, was significantly lower in the late perimenopausal group $(9.5 \pm 0.1$ vs. $9.8 \pm 0.1 \mathrm{mg} / \mathrm{dl}, p=0.03)$.

\section{Reproductive aging and serum markers of bone health}

All subjects had ALP concentrations in the normal range for this enzyme, 30-130 IU/L. In the late perimenopausal group, the concentration of ALP was higher than in the early perimenopausal group $(76.5 \pm 8.3$ vs. $58.3 \pm 2.7 \mathrm{IU} / \mathrm{L}, p<0.05)$ (Fig. 1). Correlations between the measures of reproductive aging and bone metabolism are shown in Table 2. ALP concentrations were correlated with higher mean FSH $(p=0.01)$ and higher mean LH ( $p<0.001)$ on day $6 \pm 2$ of the menstrual cycle. Additionally, there was a trend for higher ALP levels with longer cycle lengths $(p=0.06)$. An association between ALP and $E_{2}$ concentrations was not observed ( $p=0.40$ ). Serum calcium was positively associated with age $(p<0.04)$. The negative association between serum calcium and FSH was not significant $(p=0.09)$.

Table 1. Clinical Characteristics of Perimenopausal Women by Screening FSH

\begin{tabular}{|c|c|c|c|}
\hline & $\begin{array}{c}\text { Early perimenopause } \\
\text { FSH } \leq 15 \mathrm{IU} / \mathrm{L} \\
(\mathrm{n}=27)\end{array}$ & $\begin{array}{c}\text { Late perimenopause } \\
F S H \leq 15 \mathrm{IU} / \mathrm{L} \\
(\mathrm{n}=11)\end{array}$ & $\mathrm{p}$ value \\
\hline Age (years) & $46.3 \pm 0.8^{\mathrm{a}}$ & $48.6 \pm 0.9$ & $0.1^{\mathrm{b}}$ \\
\hline BMI $(\mathrm{kg} / \mathrm{m} 2)^{\mathrm{c}}$ & $23.9 \pm 0.4$ & $24.7 \pm 1.3$ & 0.5 \\
\hline Menstrual cycle length (days) & $29.6 \pm 2.3$ & $76.0 \pm 15.3$ & $0.0001^{\mathrm{b}}$ \\
\hline $\mathrm{FSH}(\mathrm{IU} / \mathrm{L})$ & $9.3 \pm 0.7$ & $39.4 \pm 6.6$ & $<0.001$ \\
\hline LH (IU /L) & $5.8 \pm 0.7$ & $23.9 \pm 4.7$ & $<0.001$ \\
\hline $\mathrm{E}_{2}(\mathrm{pg} / \mathrm{ml})$ & $71.0 \pm 11.4$ & $27.0 \pm 7.1$ & 0.006 \\
\hline $\mathrm{E}_{1}(\mathrm{pg} / \mathrm{ml})$ & $73.4 \pm 9.7$ & $48.4 \pm 9.9$ & $<0.05$ \\
\hline $\mathrm{P}(\mathrm{ng} / \mathrm{ml})$ & $0.3 \pm 0.08$ & $0.2 \pm 0.006$ & 0.4 \\
\hline $\mathrm{OV}+$ & $22 / 27(82 \%)$ & $3 / 11(27 \%)$ & $<0.003^{\mathrm{d}}$ \\
\hline Prolactin $(\mathrm{ng} / \mathrm{ml})$ & $8.3 \pm 0.7$ & $6.1 \pm 0.8$ & 0.06 \\
\hline DHEAS (ng/ml) & $971.6 \pm 94.1$ & $977.0 \pm 214.5$ & $<1.0$ \\
\hline Total T (ng/ml) & $0.3 \pm 0.02$ & $0.2 \pm 0.04$ & $<0.02$ \\
\hline Free $\mathrm{T}(\mathrm{pg} / \mathrm{ml})$ & $0.4 \pm 0.08$ & $0.9 \pm 0.2$ & 0.03 \\
\hline $\mathrm{TSH}(\mu \mathrm{U} / \mathrm{ml})$ & $2.1 \pm 0.3$ & $2.8 \pm 0.4$ & $<0.3$ \\
\hline $\mathrm{T}_{4}(\mu \mathrm{g} / \mathrm{dl})$ & $7.3 \pm 0.3$ & $6.5 \pm 0.4$ & 0.1 \\
\hline $\mathrm{T}_{3}(\mathrm{ng} / \mathrm{dl})$ & $134.0 \pm 4.6$ & $121.0 \pm 5.2$ & 0.1 \\
\hline $\operatorname{ALT}(\mathrm{U} / \mathrm{L})$ & $26.0 \pm 2.2$ & $25.3 \pm 3.0$ & $<0.9$ \\
\hline AST (U/L) & $25.4 \pm 1.6$ & $24.5 \pm 2.1$ & 0.7 \\
\hline
\end{tabular}

a Values are mean \pm SE. $t$ tests reported unless otherwise indicated.

bMann Whitney U test.

'BMI, body mass index; FSH, follicle-stimulating hormone; LH, luteinizing hormone; $\mathrm{E}_{2}$, estradiol; $\mathrm{E}_{1}$, estrone; $\mathrm{P}$, progesterone; $\mathrm{OV}+$, midluteal progesterone rise of $\geq 4 \mathrm{ng} / \mathrm{ml}$; DHEAS, dehydroepiandrosterone sulfate; $\mathrm{T}$, testosterone; $\mathrm{TSH}$, thyroid-stimulating hormone; $\mathrm{T}_{4}$, thyroxine; $\mathrm{T}_{3}$, triiodothyronine; ALT, alanine aminotransferase; AST, aspartate aminotransferase.

dFischers Exact Test 


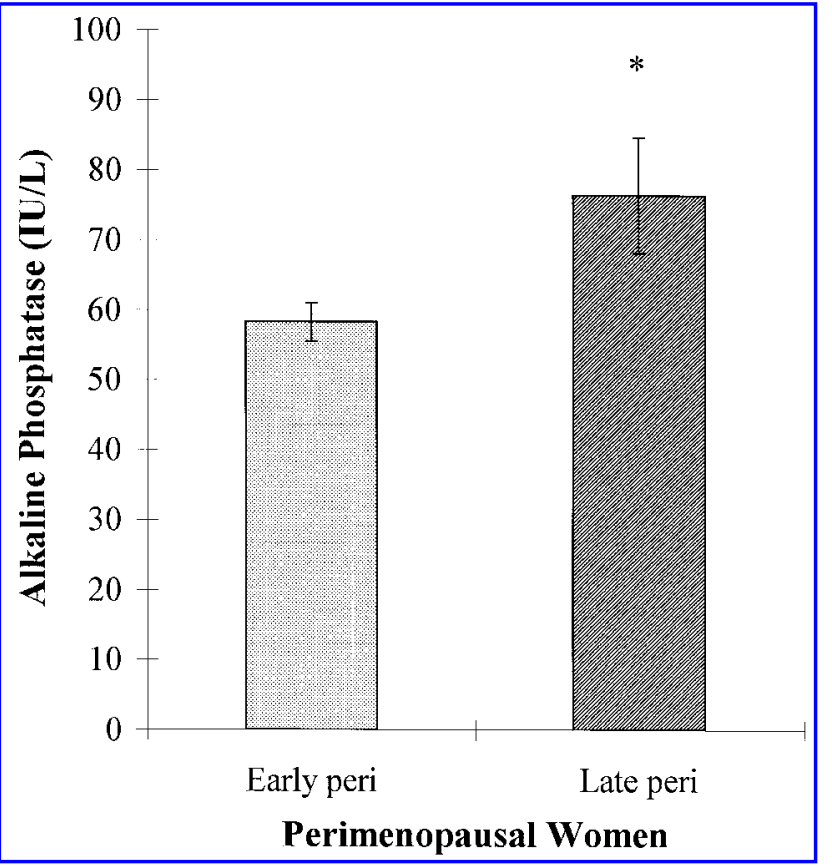

FIG. 1. Comparison of fasting serum ALP for early perimenopausal (peri) women with $\mathrm{FSH} \leq 15 \mathrm{IU} / \mathrm{L}(n=27)$ vs. late perimenopausal women with $\mathrm{FSH}>15 \mathrm{IU} / \mathrm{L}(n=$ 11 ) in the early follicular phase (menstrual cycle days 4-8). Late perimenopausal women with $\mathrm{FSH}>15 \mathrm{IU} / \mathrm{L}$ had significantly higher concentrations of serum ALP. ${ }^{*} t=$ $2.08 ; p<0.05$.

In a subsample $(n=10)$, serum ALP was positively associated with OC $(r=0.69, p<0.03)$ (Fig. 2) and showed a statistical trend with ucOC $(r=0.59, p=0.07)$. FSH was positively related to $\operatorname{ALP}(r=0.78, p<0.007)$ and ucOC $(r=0.7, p<$ $0.03)$ and showed a trend with OC $(r=0.56, p=$ $0.09)$.

The \% ucOC was higher in the group of women with $\mathrm{E}_{1}$ concentrations $<40 \mathrm{pg} / \mathrm{ml}$ compared with those with concentrations $>40 \mathrm{pg} / \mathrm{ml}(46.3 \% \pm$ $6.6 \%$ vs. $22.0 \% \pm 3.1 \%$, low $\mathrm{E}_{1}$ vs. higher $\mathrm{E}_{1}, p=$ 0.006). Women with $\mathrm{E}_{1}$ concentrations $<40 \mathrm{pg} / \mathrm{ml}$ also had $\mathrm{E}_{2}$ concentrations $<20 \mathrm{pg} / \mathrm{ml}$, representative of a low estrogen environment overall. A trend for higher \% ucOC was found in the group of women with $\mathrm{E}_{2}$ concentrations $<20 \mathrm{pg} / \mathrm{ml}$ compared with those with concentrations $>20$ $\mathrm{pg} / \mathrm{ml}\left(40.5 \% \pm 7.7 \%\right.$ vs. $22.8 \% \pm 3.7 \%$, low $\mathrm{E}_{2} \mathrm{vs}$. higher $\left.\mathrm{E}_{2}, p=0.07\right)$.

\section{DISCUSSION}

The climacteric encompasses the complete span of reproductive aging, generally considered to begin with the decline in fertility after the age of 35. In a woman's early 40s there is an increase in mean FSH concentrations and $\mathrm{LH}$ pulsatility before any reduction in estrogen or $\mathrm{P} .{ }^{20}$ Episodes of hyperestrogenism may also occur secondary to the elevated FSH and accelerated follicular development. ${ }^{4}$ Thereafter, there is a dramatic decline in the production of both $\mathrm{E}_{2}$ and $\mathrm{E}_{1}$ and notable declines in $\mathrm{T}$ and androstenedione. ${ }^{21}$ The stage of the climacteric where bone turnover accelerates has not been conclusively established. Several investigators have suggested that accelerated bone turnover commences prior to the actual menopause, but methodological weaknesses have limited the significance of their findings. $9,10,19,22-24$ These limitations include the use of single blood samples to assess sex steroid and gonadotropin concentrations, failure to synchronize the timing of blood draws in relation to the menstrual cycle, and the use of heterogeneous study samples poorly defined for menopausal status.

To better characterize the relationship between a gross marker of bone turnover (ALP) and a more precise indicator of bone activity (OC and ucOC) with reproductive aging, we used serial measures to assess sex steroids and gonadotropins in the early follicular phase of the menstrual cycle. In this way, women were classified into early or late perimenopausal groups based on the mean of 9 hourly FSH concentrations on cycle day 6 . The use

Table 2. Pearson Correlations for AlP or Calcium with Age and Markers of Reproductive Aging: FSH, LH, Cycle Length, And E $2(n=38)$

\begin{tabular}{llllll}
\hline & Age & \multicolumn{1}{c}{ FSH } & \multicolumn{1}{c}{ LH } & Cycle length & $E_{2}$ \\
\hline ALP & 0.15 & $\begin{array}{l}0.41 \\
(p=0.01)\end{array}$ & $\begin{array}{l}0.56 \\
(p<0.001)\end{array}$ & $\begin{array}{l}(p=0.31 \\
-0.06)\end{array}$ & -0.14 \\
Calcium $^{\mathrm{a}}$ & $\begin{array}{l}0.34 \\
(p<0.04)\end{array}$ & $\begin{array}{l}-0.28 \\
(p=0.09)\end{array}$ & -0.08 & -0.14 & 0.22 \\
\hline
\end{tabular}

${ }^{\mathrm{a} C}$ Corrected for serum albumin of $4.2 \mathrm{~g} / \mathrm{dl}$. 


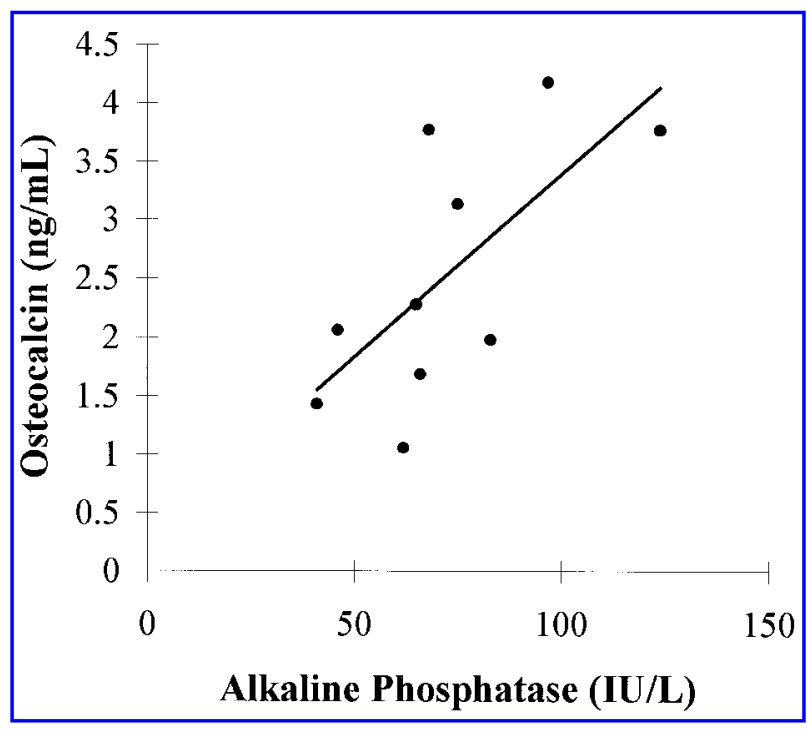

FIG. 2. Relationship between ALP and OC concentrations at 0900 hours $(r=0.69, p<0.03, n=10)$. Menstrual cycle days 4-8 for the perimenopausal women and random day for the postmenopausal woman with 18 months of amenorrhea.

of frequent blood sampling to detect dynamic FSH secretion permits a more precise determination of the true perimenopausal state. With this intensive sampling technique, we were able to detect differences in ALP concentrations associated with an FSH value $>15 \mathrm{IU} / \mathrm{L}$. This level of FSH has been shown to be indicative of early reproductive aging and is much lower than that observed in prior studies of menopausal effects on bone turnover when single estimates of FSH were obtained. 9,10,23

The higher concentrations of ALP in our late perimenopausal group would seem to be unrelated to chronological age, given the similar ages of the two study groups. Moreover, in the early perimenopausal group, the normally cycling women were significantly younger (mean age $43.2 \pm 0.7 \mathrm{vs}$. $49.5 \pm 0.8$ years, $p<0.001$ ) than those with irregular cycles, but ALP levels were similar. Thus, there appears to be no age-related influence on ALP function during the midlife years.

To what extent the observed elevation in ALP in women with an FSH value $>15$ IU/L is associated with clinical manifestations of bone loss is not known, as bone density measures were not obtained in this study. Future studies should incorporate a longitudinal design across the perimenopausal transition to assess bone biomarkers and their relation to bone density.

Previous reports have been inconsistent about the relationship between bone turnover markers or bone density and $\mathrm{E}_{2}$. Some have reported a negative relationship between bone biomarkers (OC) and $\mathrm{E}_{2},{ }^{9}$ whereas others have found no relationship between bone density and $\mathrm{E}_{2} \cdot{ }^{24}$ Despite significantly lower levels of $E_{2}$ in the late perimenopausal group, we found no relationship between day 6 mean $\mathrm{E}_{2}$ and $\operatorname{ALP}(r=-0.14, p=$ $0.40)$ when data from the entire sample were assessed. In this study, as in previous studies, $\mathrm{E}_{2}$ was determined on a single day, which may have hampered our ability to determine the more chronic estrogen environment and the true relationship to ALP activity. Additionally, a single menstrual cycle differs in length from the average remodeling cycle of bone (approximately 4-8 months) $)^{25,26}$ and, therefore, may not be capturing the total activity that gave rise to ALP concentrations at one time.

Using a new IRMA assay for intact protein (Ntact), we also demonstrated that OC is detectable, albeit at low concentrations, in healthy perimenopausal women. By this method, we were able to show for the first time that FSH is related to ucOC concentrations. The biochemical influence of the undercarboxylated species of OC is currently not known, but ucOC has been reported to predict the risk of hip fracture among elderly women. ${ }^{27}$ Moreover, ucOC concentrations were higher in postmenopausal women than in cycling women in a study where menopause was defined by recall of last menstrual period. ${ }^{14}$ Additionally, in this study, ucOC elevations occurred in concert with elevations in ALP, although not at conventional levels of significance. Thus, reproductive aging may be important in the phenomenon of elevated ucOC after menopause.

This study also reports a possible link between estrogen status and ucOC. Of particular interest is that $E_{1}$ (the predominant circulating estrogen after menopause) was a better discriminator than $\mathrm{E}_{2}$ (the dominant estrogen before menopause) in determining the degree to which OC was undercarboxylated. In our very small sample of climacteric women $(n=10)$, those with $\mathrm{E}_{1}$ concentrations $<40 \mathrm{pg} / \mathrm{ml}$ had more than a twofold increase in \% ucOC. The role that estrogen may have in the carboxylation of the bone protein is unknown and needs elucidation. Given the relatively higher free concentrations of $\mathrm{E}_{1} \mathrm{vs}$. $\mathrm{E}_{2}$ during the postmenopausal years, ${ }^{28}$ the bioactive influence of $E_{1}$ on postmenopausal bone may be underestimated. ${ }^{29}$ 


\section{CONCLUSIONS}

The findings from this cross-sectional study performed in a group of healthy perimenopausal women with well-characterized gonadotropin and sex steroid levels confirm that signs of reproductive aging (elevated gonadotropins and prolonged cycles) are associated with elevated ALP concentrations and, in turn, with OC, a more specific bone marker. To confirm the clinical significance of this finding, future studies should include measures of bone density. Measurement of ALP in healthy perimenopausal women offers a nonspecific but inexpensive marker of bone loss that is commonly determined as part of the physical examination in midlife women. Furthermore, these data suggest that health-promotion strategies for preserving bone should be instituted well before the last menstrual period.

\section{ACKNOWLEDGMENTS}

We are grateful to John Suttie, University of Wisconsin-Madison, for sharing the protocol for measuring ucOC and to Jean Engelke for technical advice with the method. We thank Alice Rolfes-Curl, Pamela Olton, and Cathy Zawacki for their work in the laboratory and acknowledge the assistance of Sue Frank, Pat Jarosz, and Mei$\mathrm{Yu}$ Yu. We appreciate the critical review by Vasantha Padmanabhan. We are especially grateful to the women who served as research subjects.

\section{REFERENCES}

1. Christiansen C, Christensen MS, Larsen NE, Transbol I. Pathophysiological mechanisms of estrogen effect on bone metabolism. Dose-response relationships in early postmenopausal women. I Clin Endocrinol Metab 1982;55:1124.

2. Richelson LS, Wahner HW, Melton JL III, Riggs BL. Relative contributions of aging and estrogen deficiency to postmenopausal bone loss. $\mathrm{N}$ Engl J Med 1984;311:1273.

3. Reame NE. Gonadotropin changes in the perimenopause. In: Lobo RA, ed. Perimenopause. New York: Springer-Verlag, 1997:157.

4. Santoro N, Brown JR, Adel T, Skurnick JH. Characterization of reproductive hormonal dynamics in the perimenopause. J Clin Endocrinol Metabol 1996;81: 1495.
5. Shaarawy M, El-Mallah SY, Hassan HE-E, Aref AI. Choice of reliable biochemical markers for assessment of bone remodeling in postmenopausal osteoporosis. Menopause 1997;4:212.

6. Seibel MJ, Baylink DJ, Farley JR, et al. Basic science and clinical utility of biochemical markers of bone turnover-A Congress report [Review]. Exp Clin Endocrinol Diabetes 1997;105:125.

7. Marcus R, Holloway L, Wells B, et al. The relationship of biochemical markers of bone turnover to bone density changes in postmenopausal women: Results from the postmenopausal estrogen/progesterone interventions (PEPI) trial. I Bone Miner Res 1999;14: 1583.

8. Nordin BEC, Polley KJ. Metabolic consequences of the menopause: A cross-sectional, longitudinal and intervention study on 557 normal postmenopausal women. Calcif Tissue Int 1987;41:S1.

9. Slemenda C, Hui SL, Longcope C, Johnston CC. Sex steroids and bone mass: A study of changes about the time of the menopause. J Clin Invest 1987;80:1261.

10. Nordin BEC, Moris HA, Need AG, Horowitz M, Robertson WG. Relationship between plasma calcium fractions, and other bone-related variables, and serum follicle-stimulating hormone levels in premenopausal, perimenopausal, and postmenopausal women. Am J Obstet Gynecol 1990;164:140.

11. Calvo MS, Eyre DR, Gundberg CM. Molecular basis and clinical application of biological markers of bone turnover. Endocr Rev 1996;17:333.

12. Brown JP, Delmas PD, Arlot M, Meunier PJ. Active bone turnover of the cortico-endosteal envelope in postmenopausal osteoporosis. I Clin Endocrinol Metabol 1987;64:954.

13. Minisola S, Pacitti MT, Romagnoli E, et al. Clinical validation of a new immunoradiometric assay for intact human osteocalcin. Calcif Tissue Int 1990;64:365.

14. Sokoll LJ, Sadowski J. Comparison of biochemical indexes for assessing vitamin $\mathrm{K}$ nutritional status in a healthy adult population. Am J Clin Nutr 1996;63:566.

15. Price PA. Vitamin K-dependent formation of bone gla protein (osteocalcin) and its function. Vitam Horm 1985;42:65.

16. Lian JB, Gundberg CM. Osteocalcin biochemical considerations and clinical applications. Clin Orthop 1988;226:267.

17. Colford J, Suiler D, Langman C. Five osteocalcin assays compared: Tracer specificity, fragment interference, and calibration. Clin Chem 1997;43:1240.

18. Toner JP, Philput CB, Jones GS, Muasher SJ. Basal follicle-stimulating hormone level is a better predictor of in vitro fertilization performance than age. Fertil Steril 1991;55:784.

19. Garton M, Martin J, New S, et al. Bone mass and metabolism in women aged 45-55. Clin Endocrinol 1996; 44:563.

20. Reame NE, Kelch RP, Beitins IZ, Yu MY, Zawacki CM, Padmanabhan V. Age effects on follicle-stimulating hormone and pulsatile luteinizing hormone secretion 
across the menstrual cycle of permenopausal women. J Clin Endocrinol Metabol 1996;81:1512.

21. Adashi EY. The climacteric ovary as a functional gonadotropin-driven androgen-producing gland. Fertil Steril 1994;62:20.

22. Ebeling PR, Atley LM, Guthrie JR, et al. Bone turnover markers and bone density across the menopausal transition. I Clin Endocrinol Metab 1996;81:3366.

23. Perrone G, Galoppi P, Capri O, Anelli G, Borrello M, Zichella L. Lumbar and femoral bone density in perimenopausal women with irregular cycles. Int J Fertil 1995;40:120.

24. Steinberg KK, Freni-Titulaer LW, DePuey EG, et al. Sex steroids and bone density in premenopausal and perimenopausal women. J Clin Endocrinol Metabol 1989;69:533.

25. Hattner R, Epker BN, Frost HM. Suggested sequential mode of control of changes in cell behavior in adult bone remodeling [Reprint]. J NIH Res 1995;7:54.

26. Parfitt AM. Bone remodeling: Relationship to the amount and structure of bone, and the pathogenesis and prevention of fractures. In: Riggs BL, Melton LJ
III, eds. Osteoporosis: Etiology, diagnosis and management. New York: Raven Press, 1988.

27. Szulc P, Chapuy MC, Meunier PJ, Delmas PD. Serum undercarboxylated osteocalcin is a marker of the risk of hip fracture in elderly women. J Clin Invest 1993; 47:1769.

28. Marcus R. New perspective on the skeletal role of estrogen [Editorial]. I Clin Endocrinol Metab 1998;83: 2236.

29. Stone K, Bauer DC, Black DM, Sklarin P, Ensrud KE, Cummings SR. Hormonal predictors of bone loss in elderly women: A prospective study. J Bone Miner Res 13;47:1167.

Address reprint requests to: Jane L. Lukacs, Ph.D., R.N. School of Nursing, Center for Nursing Research 400 North Ingalls Building, Suite 4232 University of Michigan Ann Arbor, MI 48109-0482 
This article has been cited by:

1. Jane L. Lukacs, Sarah Booth, Michael Kleerekoper, Rudi Ansbacher, Cheryl L. Rock, Nancy E. Reame. 2006. Differential associations for menopause and age in measures of vitamin $\mathrm{K}$, osteocalcin, and bone density. Menopause 13:5, 799-808. [CrossRef] 